\title{
Human infection in Tayside, Scotland due to Salmonella serotype Livingstone
}

\author{
D. C. OLD, M. PORTER-BOVERI* and D. S. MUNRO†
}

Departments of Medical Microbiology, ${ }^{*}$ Department of Public Health Medicine, Tayside Health Board, Dundee DD1 9NL, University of Dundee Medical School, Ninewells Hospital, Dundee DD1 9SY and †Scottish Salmonella Reference Laboratory, Stobhill Hospital, Glasgow G21 3UW

\begin{abstract}
Summary. Livingstone was the third most common salmonella serotype isolated from cases of human salmonellosis in the Tayside region of Scotland in 1989-1991; latterly, it spread to Grampian region. The significant upsurge of Livingstone in these two Scottish regions was not matched by similar increases in its frequency of isolation from human cases of salmonellosis in other regions of Scotland or elsewhere in the UK. Although Salmonella Livingstone is usually associated in the UK with incidents of infection among poultry flocks, our detailed investigations found no clear evidence that poultry, eggs or poultry-related products were responsible for this outbreak. Most cases occurred in the summer months from July to September and many of the patients required hospital treatment. Other than one outbreak among geriatric patients in a long-stay hospital in north Tayside, most of the cases were sporadic. The extent of the outbreak, covering 3 years, was recognised mainly because Livingstone was previously an uncommon serotype in Tayside. There were few Livingstone isolations from non-human sources in Scotland in these same years. Possible sources of infection and predisposing factors among patients are discussed. Livingstone was not isolated in Scotland in 1992.
\end{abstract}

\section{Introduction}

The first isolation of a Salmonella with the antigenic formula $6,7: \mathrm{d}: 1, \mathrm{w}$ was made in 1951 from patients with gastro-enteritis staying at a hotel at Victoria Falls. ${ }^{1}$ However, strains of Salmonella serotype Livingstone, named as recommended, ${ }^{2,3}$ have usually been isolated from food animals and animal-feed products. ${ }^{4}$ In particular, poultry is a frequent source of Salmonella Livingstone; thus, of 342 incidents due to this serotype in food animals in the UK between 1971 and 1988, $74 \%$ were associated with chickens. ${ }^{5}$ Although poultry meat is an important source of dietary protein in the UK, Livingstone strains are rarely isolated from man. For example, $<0.15 \%$ of c. 25000 salmonella infections in man in England and Wales in 1989 were caused by Livingstone strains (PHLS Communicable Disease Surveillance Centre, unpublished results). The situation in Scotland was generally similar until, between 1989 and 1991, there was a notable increase in the frequency of Livingstone isolations from man in Tayside $;{ }^{6}$ corresponding increases did not occur elsewhere in Scotland or in other parts of the UK.

This paper highlights the upsurge in the frequency of human cases of gastro-enteritis associated with Salmonella Livingstone which, over a 3-year period,

Received 24 June 1993; revised version accepted 26 July 1993. was the third ranking salmonella serotype isolated in Tayside in Scotland.

\section{Materials and methods}

\section{Bacteriology}

Specimens of faeces were examined by the enrichment and selective culture methods routinely used in the Department of Medical Microbiology, Ninewells Hospital, Dundee for the isolation of species of Campylobacter, Salmonella, Shigella and, where appropriate, for Clostridium difficile and verotoxinproducing strains of Escherichia coli of serogroup O157. For patients with a history of foreign travel, species of Aeromonas and Vibrio were also sought and their faeces were examined microscopically for the presence of intestinal parasites, ova and cysts.

For the isolation of salmonellae, faeces were plated directly on Deoxycholate Citrate Agar (DCA ; CM 35, Oxoid) and incubated overnight at $37^{\circ} \mathrm{C}$. For enrichment of salmonellae, samples of faeces were inoculated in $10 \mathrm{ml}$ of Tetrathionate Broth (CM 29, Oxoid) containing iodine solution $2 \% \mathrm{v} / \mathrm{v}$, and also, for samples from patients who had been abroad, in $5 \mathrm{ml}$ of Selenite Broth (CM 395, Oxoid) containing sodium biselenite (L121, Oxoid) $4 \mathrm{~g} / \mathrm{L}$; after overnight 
incubation at $37^{\circ} \mathrm{C}$, loopfuls of enriched broth(s) were plated on DCA and incubated, as above.

Lactose non-fermenting colonies present on DCA were identified as salmonellae by their reactions in a set of 11 biochemical tests, according to departmental protocol. Serological confirmation of the O serogroup of any salmonella-like organism was made with commercially available antisera (serogroups A-G inclusive; Burroughs Wellcome Ltd) in slide agglutination tests by standard procedures. Peripheral areas in Tayside region not covered by the Dundee laboratory are served by laboratories situated at The Royal Infirmary, Perth and Stracathro Hospital, Brechin; their protocols follow closely the procedures described above.

Salmonellae were also isolated from other clinical specimens such as urine or blood, in some patients.

\section{Confirmation of identity and serotype}

Any isolate behaving biochemically and serologically like salmonellae, and isolated from a new case of infection, was sent to the Scottish Salmonella Reference Laboratory (SSRL), Stobhill Hospital, Glasgow, for further characterisation. Pure cultures were identified according to the standard biochemical protocol used at SSRL. ${ }^{7}$ Each isolate was serotyped and, where appropriate, phage typed at the SSRL according to standard procedures. ${ }^{7}$

\section{Environmental follow-up}

Information on serotype and phage type was conveyed to one of us (M.P.B.) who arranged for completion by an environmental health officer of a standard gastrointestinal enquiry form which included personal identification data together with details of foreign travel, food history and clinical features. For some patients, clinical features were supplemented by data from medical records.

\section{Results}

Salmonellae isolated from man in Tayside, 1989-1991

In the years 1989-1991, 375 new cases of human salmonellosis were identified by the Dundee laboratory. Of three persons from whom multiple serotypes were isolated, one produced four serotypes. ${ }^{8}$ Although some patients yielded salmonellae from different kinds of clinical specimens, there were only 10 patients whose salmonellae were isolated exclusively from sites other than faeces. Of the 380 salmonellae isolated from these 375 new cases of salmonellosis, the most common

Table I. Salmonellae isolated from man in Tayside, 1989-1991

\begin{tabular}{lccc}
\hline & \multicolumn{3}{c}{$\begin{array}{c}\text { Number associated with new cases of } \\
\text { human infection in }\end{array}$} \\
\cline { 2 - 4 } Serotype & Dundee & $\begin{array}{c}\text { Angus, and Perth } \\
\text { and Kinross }\end{array}$ & Tayside \\
\hline Enteritidis & 198 & 110 & 308 \\
Typhimurium & 52 & 50 & 102 \\
Livingstone & 51 & 20 & 71 \\
Virchow & 26 & 11 & 37 \\
Others* & 53 & 37 & 90 \\
All & 380 & 228 & 608 \\
& & & \\
\hline
\end{tabular}

* See text.

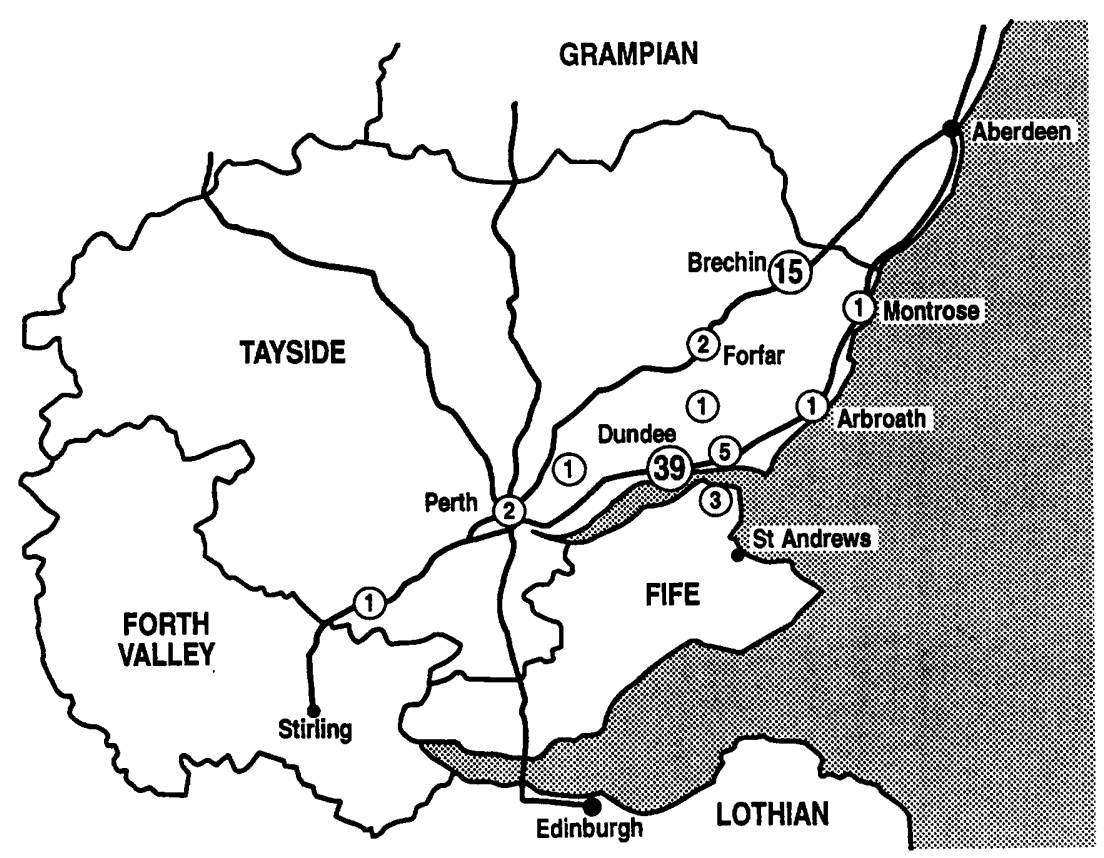

Fig. 1. Distribution of human cases of Livingstone in 1989-1991 in the area served by Tayside Health Board. Numbers circled represent infected patients in the area shown. 
Table II. Isolations of Salmonella Livingstone in Scotland, 1986-1991

\begin{tabular}{ccc}
\hline & \multicolumn{2}{c}{ Number of isolations from } \\
\cline { 2 - 3 } Year & man & other sources \\
& & \\
\hline 1986 & $25(1)^{*}$ & 46 \\
1987 & $11(1)$ & 3 \\
1988 & $9(2)$ & 2 \\
1989 & $28(24)$ & 3 \\
1990 & $48(40)$ & 5 \\
1991 & $19(7)$ & 3 \\
Total & $140(75)$ & 62 \\
\end{tabular}

* Numbers of isolates from man in Tayside in parentheses.

Table III. Age and sex distribution of Livingstone cases in Tayside, 1989-1991

\begin{tabular}{cccc}
\hline $\begin{array}{c}\text { Age group } \\
\text { (years) }\end{array}$ & Males & Females & All \\
\hline$<1$ & 3 & 0 & 3 \\
$1-4$ & 3 & 0 & 3 \\
$5-14$ & 0 & 0 & 0 \\
$15-24$ & 2 & 3 & 5 \\
$25-34$ & 5 & 3 & 8 \\
$35-44$ & 6 & 4 & 10 \\
$45-54$ & 5 & 4 & 9 \\
$55-64$ & 0 & 2 & 2 \\
$65-74$ & 3 & 6 & 9 \\
$75-84$ & 4 & 10 & 14 \\
$>85$ & 2 & 6 & 71 \\
All & 33 & 38 & \\
\hline
\end{tabular}

serotypes were Enteritidis (52.1\%), Typhimurium (13.7\%), Livingstone (13.4\%) and Virchow (6.8\%); the remaining $13.9 \%$ of isolates comprised 53 strains of a further 30 serotypes, none of which accounted for $>1.5 \%$ of the total (table I).

The laboratory at Dundee serves a catchment area greater than the city itself including, for example, parts of north-east Fife; hence, not all of the 380 new salmonella isolations identified in Dundee in 19891991 came from Dundee residents. Again, a few isolations were made from patients resident in other parts of Tayside or north-east Fife, but hospitalised in Dundee. Accordingly, for completeness of data, the salmonellae isolated from persons resident in the Angus and Perth and Kinross districts of Tayside should also be considered. In that same 3-year period, our peripheral laboratories in Perth and Stracathro identified 228 new cases of salmonellosis in man. The most common serotypes were Enteritidis $(48.2 \%)$, Typhimurium $(21.9 \%)$, Livingstone $(8.8 \%)$ and Virchow $(4.8 \%)$; the remaining $16.2 \%$ of isolates comprised 37 strains belonging to a further 23 serotypes, of which only Stanley (six cases) and Thompson (five) accounted for $>1 \%$ of the total (table I). Fifteen of the additional 20 Livingstone cases identified by the laboratories at Perth and Stracathro were associated with a food-poisoning outbreak that occurred at a hospital in north Tayside in the summer of 1990, with 14 in-patients on wards for the elderly and one staff member affected; the other five cases were sporadic.

The 71 Livingstone cases occurred in 1989 ( 24 cases), 1990 (40) and 1991 (7); they were distributed in the Tayside districts of Angus (20), Dundee (44) and Perth and Kinross (4); the remaining three cases came from north-east Fife, which is also served by the Dundee laboratory (fig. 1).

\section{Livingstone isolations from non-human sources, 1986-1991}

The numbers of isolations of Livingstone recorded in Scotland from sources other than man from 1986 to 1991 are shown in table II; 46 (74\%) of the 62 isolates from non-human sources were reported in 1986, the only other year before the Tayside outbreak in which there had been much Livingstone infection in man in Scotland. Again, it is of interest that, whilst laboratories widely distributed throughout Scotland submit cultures of Salmonella spp. from human and nonhuman sources to SSRL for confirmation of identity and serotyping, only seven (11\%) isolates of Livingstone originated from laboratories in the west of Scotland. Many isolates came from poultry (33) or from eggs, poultry by-products and poultry-associated environments (five); there were isolates from a dog and a horse (one each). Environmental sources including abattoirs, hospital-kitchen drains and sewage sludge accounted for the remaining 22 isolates.

\section{Patients and histories}

Among the 71 cases of Livingstone infection in Tayside, there was no significant difference between the numbers of male (33) and female (38) patients (ratio, 1:1.15). Their average age was 53 years (range 0.5-95 years), skewed by an average age of 80 years for the 14 elderly patients in the hospital outbreak in 1990; without them, it was only 46 years. The age-sex distribution of the patients from whom Livingstone was isolated in Tayside is shown in table III.

In this series of patients, many of whom had predisposing factors other than age, eight $(11.3 \%)$ had a gastric or duodenal ulcer; three ulcer patients had undergone surgical treatment and were taking $\mathrm{H}_{2}$ antagonists. Ten patients had had a cholecystectomy, two of whom had also had gastrointestinal surgery. Seven patients had an underlying systemic disorder, e.g., diabetes mellitus or HIV infection. Three were receiving antibiotic or antifungal treatment during the time that they were exposed to Livingstone and one person was taking anti-histamine treatment for Meniere's disease. At least seven patients gave a history of taking non-steroidal anti-inflammatory drugs. Underlying neoplastic disease co-existed in four patients and was suspected, and later confirmed, in a 


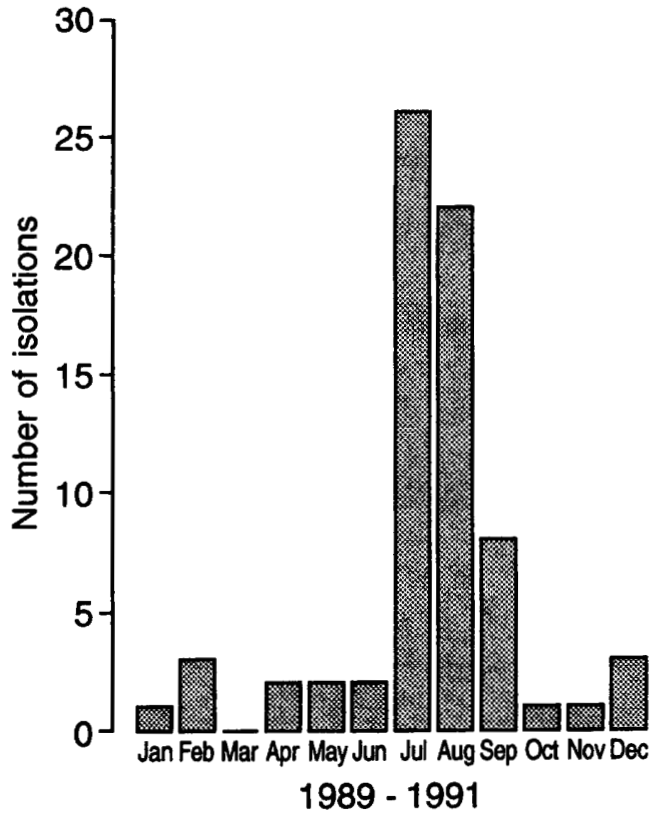

Fig. 2. Numbers of Livingstone infections in man by month identified in Tayside from Jan. 1989 to Dec. 1991.

further two at the time of infection. Excessive alcohol intake was confirmed in two patients and suspected in another three. Twenty-one persons were admitted to hospital as a result of their infection; another two, admitted for other reasons, were found to have Livingstone infection whilst in hospital.

Livingstone was isolated from the faeces of 69 patients; in two of these patients it was also present in apparently significant numbers in mid-stream specimens of urine. It was isolated from the blood of the remaining two patients whilst hospitalised. Two patients had apparently acquired their Livingstone infection while abroad in Majorca and Morocco. Four patients had concurrent infection with other gastrointestinal pathogens: two with Campylobacter spp. and one each with E. coli $\mathrm{O} 157$ and Salmonella Enteritidis (phage type 4). Although most patients excreted Livingstone for $c$. 1-3 weeks, a few did so for 4-9 months.

From the aggregative data illustrative of the 3-year period under study (fig. 2), there was a clear seasonal distribution with $56(79 \%)$ of the 71 Livingstone cases identified from July to September. This pattern is similar to that for all other salmonella serotypes isolated concurrently in Tayside and, indeed, the same pattern as seen in the whole of Scotland (data not shown).

\section{Discussion}

Among the 2324 serotypes of Salmonella now recognised, ${ }^{2}$ only a few, perhaps no more than 50 or so, have appeared regularly in the ranking order of the 10 most commonly reported serotypes isolated from human cases of salmonellosis worldwide over several decades $;{ }^{9}$ indeed, in most countries a few serotypes are dominant at any one time. ${ }^{10}$

At intervals, significant increases occur in the frequency of isolation of particular strains of Salmonella that may be new epidemic strains of established serotypes or even "new" serotypes. ${ }^{10-12}$ The emergence from relative obscurity of a previously exotic serotype to a position of dominance often coincides with its introduction into animal food chains through imported protein. Contamination of the mills of only a few compounders would be enough to cause widespread infection and, once entrenched in domestic animals, spillover to man is readily facilitated; the subsequent spread of a once rare serotype may be limited or extended. For example, serotypes Agona and Hadar, rarely encountered before 1969, surged to global prominence in the following decade and declined equally rapidly thereafter. ${ }^{11-14}$ In contrast, recent reports highlighting limited increases in the UK in the frequency of isolation from man of unusual serotypes of Salmonella, e.g., Ealing, Falkensee, Goldcoast, Kedougou, Manchester, Mikawasima and Wangata, have generally suggested associations with particular foods or food products, sometimes as exotic as the serotypes themselves. The spread of new serotypes locally or nationally probably depends on the extent of distribution of the incriminated foodstuff.

The emergence of Livingstone in Tayside, and its establishment as the second ranking salmonella serotype in Dundee in 1989 and 1990, was not accompanied by similar increases in the rest of Scotland and the common serotypes prevalent elsewhere in the $\mathrm{UK}^{15}$ were, apart from Livingstone, the same as those in Tayside. That the isolations were made in three laboratories confirms the reality of the findings. Scrutiny of our annual salmonella data revealed that the first isolation of Livingstone in Dundee was made in 1985 with a total of five isolations in Tayside in 1985-1988 (table II). Even in 1986, the other year in which Livingstone was prominent in Scotland (table II), only one of the 25 human isolates came from a Tayside resident (from Arbroath in Angus district). It is remarkable, therefore, that so many $(77 \%)$ of the human isolations in Scotland in 1989-1991 were made in Tayside and curious that most $(87.5 \%)$ of the other 24 human isolations were reported by laboratories in other health boards also located in the east of Scotland: 17 isolates from Grampian and one each from Borders, Fife, Lothian and Forth Valley (this latter from a patient later found to be a Tayside resident). Thus, laboratories in two health boards (Tayside and Grampian) servicing only $17 \%$ of the Scottish population reported $94 \%$ of all isolations of Livingstone from man in 1989-1991. In contrast, only three isolates were identified by laboratories serving two health boards (Greater Glasgow and Dumfries and Galloway) in the west of Scotland and these came from patients resident in Glasgow, Paisley and Dumfries. The marked difference in geographical distri- 
bution of cases between the east and west of Scotland is intriguing but unlikely to be explained by corresponding variations in laboratory protocols or more active salmonella surveillance by laboratories in the east of Scotland. Whether the observed difference relates to different agricultural practices, climate, local food distribution or food preferences is, as yet, unknown. However, corresponding differences between the east and west of Scotland have also been noted for cases of infection due to $E$. coli 0157 (Dr J. C. M. Sharp, personal communication).

It is difficult to explain why serotype Livingstone should have emerged so dramatically in Tayside in 1989-1991, accounting for c. $12 \%$ of 608 salmonella incidents reported there. Many of the Livingstone cases in Tayside were among the elderly, e.g., $46 \%$ in patients $>55$ years of age. Even excluding the elderly cases associated with the hospital outbreak in 1990, the frequency of infection by Livingstone (34\%) in that age group was twice that of all other salmonella serotypes. However, no association with organisations relevant to the elderly, such as "Meals-on-Wheels", day-care hospitals or drop-in centres, was established. The only cluster of cases observed in this series was also among the elderly, i.e., in the hospital outbreak at Brechin in 1990. Although its source was never definitively identified, infection there was believed to have been introduced to the kitchen from poultry and spread to have occurred by cross-contamination.

Other than that incident, most cases were sporadic and commonality of infection was suspected only because an uncommon serotype was involved. Despite extensive enquiries, no connections among other cases were established. Thus, the individuals involved had eaten a wide variety of foods prepared in a variety of ways; shops from which private purchases had been made were not the same for all and retailers did not have common suppliers. Meals eaten at food establishments identified by individuals as possible sources of their illness were not the same in content or in preparation and the food establishments did not identify common suppliers.

Of 208 Livingstone strains isolated from human foods in England and Wales between 1988 and 1992, $183(88 \%)$ were from eggs, $16(7 \cdot 7 \%)$ from poultry and nine $(4.3 \%)$ from other foods (Dr B. Rowe, personal communication). In contrast, Livingstone isolates from human food sources in Scotland were more likely to have come from poultry than other poultry-related products including eggs. Thus, whilst it might seem reasonable to suggest that a locally distributed, poultry food was the vehicle of infection in the east of Scotland, we uncovered no evidence to substantiate that hypothesis. If, nevertheless, Livingstone did emerge in the east of Scotland because of some unidentified local food product or food distributor, that putative agent has probably disappeared, or been suppressed, because no cases of Livingstone infection were recorded in Tayside or Grampian after September 1991. Nor were there any reports of human or animal isolations in Scotland in 1992.

Since the introduction of pasteurisation of milk in Scotland in $1983,{ }^{16}$ poultry meat from chickens and turkeys has assumed a primary role in human salmonellosis there. ${ }^{17-19}$ Although salmonellosis is a minor problem in terms of poultry health, contamination of poultry meat and poultry products by salmonellae is a major risk to man. Poultry meat now accounts for $>50 \%$ of all human outbreaks in Scotland, with poultry the single most important vehicle of food-borne salmonellosis ${ }^{17,18}$ the situation is similar in England and Wales. ${ }^{20}$ Confirmation that contaminated poultry represents a major source of food-borne salmonellosis came from studies showing the similarity between the serotypes (and phage types of major serotypes) isolated from poultry and poultry meats and those isolated contemporaneously from human outbreaks. ${ }^{7,17,20}$

In these Scottish studies, however, some important differences were noted among strains isolated from poultry and man. ${ }^{17,18}$ For example, among salmonellae isolated from chicken and turkey in 10 or more incidents between 1976 and 1987, serotype Worthington $(11.9 \%)$ ranked second only to Typhimurium $(26 \cdot 1 \%)$ and was the dominant serotype in turkeys during 1977-1980, yet it never ranked among the top 10 salmonella serotypes isolated from man between 1968 and $1987 .{ }^{17,18}$ Similarly, of 421 poultry incidents due to salmonellae in 1976-1987, 319 were associated with chickens and serotype Livingstone (9.1\%) was third after Typhimurium $(31.7 \%)$ and Virchow $(11.3 \%)$ in the top-ten rankings of chicken-associated salmonella serotypes $;^{18}$ indeed, since its first emergence in 1983 as an important serotype in poultry flocks in Scotland, it ranked second (22\%) only to Typhimurium (33\%) in 1983-1987..$^{18}$ Most of the isolations responsible for that high ranking occurred in 1985 and were associated with one company among whose stock Livingstone was then, but not now, widespread. ${ }^{17}$ However, the present localised outbreak in Tayside and Grampian occurred during 3 years in which there were only 11 isolations (nine from poultry, eggs or poultry products) from non-human sources throughout Scotland (table II).

Commenting upon the low incidence of Livingstone infection in man, Reilly et al. ${ }^{17}$ suggested that it might be a Salmonella serotype with low virulence for man. Its considerable distribution over time and place, as reported here, may render that hypothesis unlikely unless, perhaps, Livingstone has manifested itself only in persons more likely to develop illness. Whilst many of the clinical cases reported here were predisposed by old age, underlying disease, pre-existing gastrointestinal disorders or other alterations of the gastrointestinal environment that could reduce resistance to salmonella infection, it is hard to believe that such predisposing factors are peculiar to Tayside residents. The finding that a few persons had no apparent predisposition may suggest a much higher incidence of 
Livingstone infection in the population than we detected.

It remains to be established whether the strain that emerged in Tayside expresses virulence determinants not seen in other Livingstone strains. Such an argument has been advanced to explain apparent differences in the epidemiology of serotype Sofia (subsp. II $1,4,12,27: \mathrm{b}:[\mathrm{e}, \mathrm{n}, \mathrm{x}])$; although the incidence of isolation of this Salmonella serotype has risen dramatically in poultry in both Australia and Israel, the incidence of its isolation from the human population is much higher in Israel than Australia. ${ }^{21}$ The results of similar experiments to identify genetic differences among Livingstone strains will be reported elsewhere.

Like most non-typhoidal salmonellae, Livingstone may become invasive, especially in patients compromised by factors that heighten susceptibility. Extraintestinal isolations of Livingstone in this series numbered four: (i) it was isolated from blood cultures of two female patients in the seventh and eighth decades of life, i.e., in line with the findings of Wilkins and Roberts for an extended series of non-typhoidal, extraintestinal salmonelloses; ${ }^{22}$ (ii) the significance of its isolation from urine in another two patients was more difficult to assess because both had gastro-enteritis and also yielded faecal isolates. Several investigators have used the ratio of blood:all isolates as a measure of invasiveness $;^{22}$ by that criterion, Livingstone $(3 \%)$ was no more invasive than most other common nontyphoidal salmonellae and clearly less so than Choleraesuis, Dublin, London, Panama and Virchow. ${ }^{22}$ Nevertheless, a high proportion $(38 \%)$ of our cases (and excluding the geriatric patients associated with the hospital outbreak) were hospitalised directly as a result of their Livingstone infection, a figure appar- ently much higher than those reported for some invasive serotypes in food-borne outbreaks. ${ }^{23-25}$ Again, it is of interest that a few patients continued to excrete Livingstone for 4-9 months, but whether that asymptomatic carriage resulted from some underlying focus of infection or inapparent predisposition is not known.

In recent editions of the Kauffmann-White scheme, ${ }^{2}$ some serotype names have been deleted, including those given to serotype variants converted by phage lysogenisation. By that convention serotype Eimsbuettel $(6,7,14: \mathrm{d}: 1, \mathrm{w})$ is considered to be a phageconvertible variant of Livingstone and so is termed Livingstone var $14^{+}{ }^{2}$ It is important, therefore, to emphasise that this paper has considered only Livingstone $(6,7: \mathrm{d}: 1, \mathrm{w})$ sensu stricto. Of the nine Eimsbuettel incidents recorded in food animals in 1977-1988 (compared with 342 for Livingstone in the same period), ${ }^{5}$ only five were fowl-associated and sheep and pigs were involved in the others. These findings might suggest that Eimsbuettel is not as well entrenched in poultry as Livingstone. However, in Scotland most $(>95 \%)$ Eimsbuettel isolates from non-human sources in 1989-1992 came from poultry (unpublished results). Although Eimsbuettel was responsible for a large outbreak in a Glasgow maternity hospital in $1986,{ }^{26}$ it has been isolated infrequently since-only 22 isolates from man in Scotland in 1987-1992. During the years of this study, individual animals or patients never yielded isolates of both serotypes, strains of which are distinguishable by biotyping, plasmid analysis and RFLP type (unpublished results).

We thank Mr H. Mather, Mrs A. Taylor and Mrs J. Valentine for expert assistance at different stages of this study.

\section{References}

1. Picton WHA, Stirrup W, Price A, Taylor J. A new salmonella type (Salm. livingstone). J Pathol Bacteriol 1953; 66: 310-312.

2. Popoff MY, Le Minor L. Antigenic formulas of the Salmonella serovars, 6th rvn. Paris, WHO Collaborating Centre for Reference and Research on Salmonella, Institut Pasteur, France. 1992: 1-145.

3. Old DC. Nomenclature of Salmonella. J Med Microbiol 1992; 37: $361-363$.

4. Odongo MO, McLaren IM, Smith JE, Wray C. A biotyping scheme for Salmonella livingstone. Br Vet J 1990; 146: 75-79.

5. Ministry of Agriculture, Fisheries and Food. Animal salmonellosis annual summary. 1988: 1-58.

6. Old DC, Porter-Boveri M, Munro DS. Recent emergence of Salmonella of serotype Livingstone in and around Dundee. Communicable Diseases (Scotland) Weekly Report 1990; 34: 6-10.

7. Reilly WJ, Oboegbulem SI, Munro DS, Forbes GI. The epidemiological relationship between Salmonella isolated from poultry meat and sewage effluents at a long-stay hospital. Epidemiol Infect 1991; 106: 1-10.

8. Old DC, Mather H. A surfeit of salmonella serotypes since a sojourn in Salou. Communicable Diseases (Scotland) Weekly Report 1990; 25 : 7-9.
9. Turnbull PCB. Food poisoning with special reference to Salmonella -its epidemiology, pathogenesis and control. Clin Gastroenterol 1979; 8: 663-714.

10. Anderson ES. The phage typing of salmonellae other than $S$. typhi. In: Oye E van (ed) The world problem of salmonellosis. The Hague, W. Junk. 1964: 91-110.

11. Lee JA. Recent trends in human salmonellosis in England and Wales: the epidemiology of prevalent serotypes other than Salmonella typhimurium. J Hyg 1974; 72: 185-195.

12. Palmer SR, Rowe B. Trends in salmonella infections. PHLS Microbiol Dig 1986; 3: 18-21.

13. Clark GM, Kaufmann AF, Gangarosa EJ, Thompson MA. Epidemiology of an international outbreak of Salmonella agona. Lancet $1973 ; 2$ : 490-493.

14. Kirby D, Wray C. Veterinary aspects and prospects for control. PHLS Microbiol Dig 1986; 3: 26-27.

15. Threlfall EJ, Rowe B, Ward LR. Recent changes in the occurrence of antibiotic resistance in Salmonella isolated in England and Wales. PHLS Microbiol Dig 1992; 9: 69-71.

16. Sharp JCM, Paterson GM, Barrett NJ. Pasteurisation and the control of milkborne infection in Britain. $B M J 1985 ; 291$ : 463-464.

17. Reilly WJ, Forbes GI, Sharp JCM, Oboegbulem SI, Collier PW, Paterson GM. Poultry-borne salmonellosis in Scotland. Epidemiol Infect 1988; 101 : 115-122.

18. Oboegbulem SI. Poultry meat and human salmonellosis: establishing the epidemiological relationship. PhD thesis, University of Glasgow. 1990. 
19. Reilly WJ. Animal husbandry and human health. Rev Med Microbiol 1991; 2: 170-176.

20. Humphrey TJ, Mead GC, Rowe B. Poultry meat as a source of human salmonellosis in England and Wales. Epidemiological overview. Epidemiol Infect 1988; 100: 175-184.

21. Harrington CS, Lanser JA, Manning PA, Murray CJ. Epidemiology of Salmonella sofia in Australia. Appl Environ Microbiol 1991; 57: 223-227.

22. Wilkins EGL, Roberts C. Extraintestinal salmonellosis. Epidemiol Infect 1988; 100: 361-368.
23. Mani V, Brennand J, Mandal BK. Invasive illness with Salmonella virchow infection. BMJ 1974; 2: 143-144.

24. Todd WTA, Murdoch JM. Salmonella virchow: a cause of significant blood stream invasion. Scott Med J 1983; 28: 176-178.

25. Small RG, Sharp JCM. A milk-borne outbreak due to Salmonella dublin. J Hyg 1979; 82: 95-100.

26. McAllister TA, Roud JA, Marshall A, Holland BM, Turner

TL. Outbreak of Salmonella eimsbuettel in newborn infants spread by rectal thermometers. Lancet 1986; 1: 1262-1264. 